\title{
Lagrange and his Mécanique Analytique: from Kantian noumenon to present applications
}

\author{
Alberto Carpinteri · Marco Paggi
}

Received: 27 November 2013/ Accepted: 14 December 2013/Published online: 21 January 2014

(C) Springer Science+Business Media Dordrecht 2014

\begin{abstract}
The deduction of most of the fundamental laws governing solid and fluid mechanics is due to Lagrange. As already mentioned by several researchers and science historians, analytical mechanics has achieved the highest degree of perfection thanks to Lagrange's work. The aim of this editorial is to provide a critical review of the second edition of Mécanique Analytique, which has been considered Lagrange's opera summa, and to illustrate the influence of such a treatise on modern mechanics. Particular emphasis will be given to the current perspectives of Lagrange's work in relation to the many mathematical and engineering developments that have been inspired by it.
\end{abstract}

Keywords Lagrange - Mécanique Analytique · Principle of virtual work - Calculus of variations . Method of variation of the arbitrary constants

On the occasion of the 200th Anniversary of G. L. Lagrange's death (1813-2013).

A. Carpinteri $(\bowtie)$

Department of Structural, Geotechnical and Building Engineering, Polytechnic University of Turin, C.so Duca degli Abruzzi 24, 10129 Turin, Italy

e-mail: alberto.carpinteri@polito.it

M. Paggi

IMT Institute for Advanced Studies Lucca, Piazza San

Francesco 19, 55100 Lucca, Italy

e-mail: marco.paggi@imtlucca.it

\section{Introduction}

1.1 Biographical review and cultural influences

The historical and philosophical analysis of Lagrange does not seem less complex than the purely scientific and mathematical one [1]. This is because of the allembracing and universal nature of his work, the depth of his analyses, the power of his synthesis, the cosmopolitan nature of his life, and because of the strength, but at the same time simplicity, of his personal nature. A nature which, on the point of death, made him so describe his fateful passing away in a serene and almost Socratic way [2]: "I was very ill the day before yesterday, my moral and physical faculties were extinguishing a little at a time; I observed the very gradual progression of the diminishing of my powers with pleasure and arrived at the end without pain, without regret, and with a very sweet descent. Oh, one shouldn't be afraid of death and, when it arrives without pain, it is a last function of life, neither painful nor unpleasant $[\ldots]$ ".

Lagrange, apart from being the great mathematician that we know well, appears to have also had a remarkable cultural, humanistic, and philosophic background [3]. Having obtained a university diploma in Law at only 16, in order to satisfy the wishes of his father, he continued his studies under the guide of the Abbot Giambattista Beccaria, an eminent physicist and mathematician from Turin University, an empiricist and continuator of that humanistic course of 
studies of the scientific culture that originated from the Italian Renaissance and which always remained clearly distinct from the French eighteenth century Encyclopedism. Lagrange without doubt belonged to his era, the Era of the Enlightenment [4], with all the immense faith that this current of thought entrusted in the capacity of Man, interpreter of Nature and creator of his own destiny. One of his many biographers, Cossali, defined him as "The most metaphysical analyst", where the term "metaphysical" should be intended in Kant's meaning of "independent of experience". Another of his biographers, Delambre, revealed the wide ranging intellectual profile of Lagrange: his interests covered such topics as metaphysics, the history of culture and of religions, linguistics, medicine, botany, and above all chemistry.

Lagrange never wanted to be portrayed in any manner, believing, like a Neoplatonic philosopher, that only his work deserved to be passed on for posterity. This desire can be confirmed by the intention, declared in an apposite note at the beginning of his greatest work, Mécanique Analytique, of never and in no case using explicative figures: "Figures will not in fact be found in this work. The methods that I show do not require geometrical constructions or mechanical reasonings, but only algebraic operations, subject to a regular and uniform development. Whoever loves Analysis will with pleasure see Mechanics become a new branch, and they will be grateful to me for having thus extended the domain". It is not by chance that Lagrange, at the beginning of his maximum treatise, emphasised his intention in this manner, an intention that was also shared by his illustrious colleagues. In this sentence can be found all the longing, so typical of the llluminists, of becoming free of contingency, of appearance, of the unpredictable nature of certain scholastic methods.

Two important pupils of Lagrange, Biot and Poisson, commemorating their Mentor, affirmed that only he could offer mathematicians "the model of that almost ideal perfection that it is necessary to force oneself to reach". Biot and Poisson concluded with a moving recollection of Lagrange's great modesty: "This man, who knew so many things, was surprised above all by what he didn't know. These simple words, "I don't know", were his favourite expression...". Yet again a Socratic attitude emerges, as witnessed by his closest collaborators.
In 1819, Giambattista Magistrini, a teacher of Sublime Calculus at the University of Bologna, in his inaugural lecture for the academic year, openly praised the historical introductions that Lagrange usually put before his works: "Primarily of very noble value, and greatly enlightening of his production, are those prospects that he proposed in front of anyone on the origin, on the progresses and on the current state of affairs of each branch of Science, that he undertook to examine". A characteristic that distinguished him from all his eminent contemporary colleagues, including Euler, was that of framing his most significant works in a historical studies context. This bestows on him once again, if it were necessary, his particular attitude of great cultural open-mindedness.

His empiricist formation, his attention to the reality of the experimentation and to the objectivity of measurements, can be found in extensive evidence, of which mention can be made to the activity carried out in Paris for the Weight and Measures Commission. Burzio [5] stated: "It is said that it is due to the discrete sarcasm of Lagrange that the number 12 was not adopted as the basis of the metric system instead of 10 : with the purpose of explaining to the doubtful members of the commission the absurdity of a base of 12, Lagrange proposed 11 as being better; but the disadvantages of this base were so evident that the Commission understood the irony and opted for 10 ".

Finally, it should be observed how the studies of the last decades have in particular been directed towards the figure of Euler [6], and have become side-tracked from the figure of Lagrange. A similar slowing down of interest was witnessed in the nineteenth century for the works of Leibniz, because of the prevalent interest in Newton [3].

\subsection{The philosophical context of Lagrange activity}

Lagrange and Newton can be put together due to the fact that they were both aware of a certain tiredness and saturation towards purely mathematical studies, once their most important works had been published: the Mécanique Analitique and the Principia. Both turned to humanistic, historical and philosophical studies, in order to satisfy interests they previously had or perhaps to find vaster environments into which they could place and contemplate their most relevant results. Bell [7] stated: "This nausea towards anything 
that had the odour of mathematics pushed Lagrange towards the questions that he considered worthy of his interest, in the exact same way Newton had done after Principia.... In this strange diversity, he used to surprise his friends with his extensive knowledge and with his penetration of his spirit into fields that had nothing to do with mathematics".

However, both Burzio [5] and the other biographers considered Lagrange as a "pure scientist", a "specialist", so different, even in this, from his contemporary colleagues or those that preceded him, who often mixed purely scientific discussions with digressions of a metaphysical or even theological nature (see Pascal, Newton, Leibniz, and Euler). Lagrange remained rigorously outside all of this, although without the harshness of a certain Enlightenment of manner. For this reason, he was considered a model by the Positivism philosophers, from Comte to Renan and even to Mach. Comte maintained "the eminent philosophical superiority of Lagrange over all the geometricians subsequent to Descartes and Leibniz". In this sense, he is prevalently considered a prepositivist. On the other hand, his enlightened, and in particular his Kantian character, has perhaps not been emphasised enough.

It should be observed that, although Immanuel Kant was part of the Prussian Academy of Sciences (Preussische Akademie der Wissenchaften, 1700-1945) in the Historical and Philosophical Class, and although he lived in Prussia (to be precise in Koenigsberg, in Eastern Prussia), in the 20 years period in which Lagrange directed the Physics, Mathematics, and Natural Science Class, it does not appear that the two ever had contact, either direct or epistolar. As is well known, most of the correspondence of Lagrange dating back to the Berlin period has been lost. This is to a great extent due to political reasons which saw the Prussian State set against France, first revolutionary and then Napoleonic. To a lesser extent, another reason could be due to the fact that Lagrange himself, during the French revolution, had to destroy part of his correspondence for reasons of personal safety. All this occurred although Lagrange, and Kant for that matter, had never explicitly dedicated his works to his powerful protectors: first Frederick II of Prussia and then Napoleon.

In Berlin, Lagrange was a court mathematician and, as such, he generally spoke in French, while Kant was a philosopher who was more connected to the academia and who usually spoke in German. This obviously does not rule out that they could have communicated, although no traces of such a possible relationship remain. When, in 1786, Immanuel Kant was welcomed by the Berlin Academy of Sciences, he was by then one of the most famous philosophers in Europe, just like Lagrange could be numbered among the most eminent mathematicians of that time.

For Kant, it is necessary to distinguish the phenomena that represent the immanent reality and therefore the shadows in the Plato's Myth of the Cave, from the noumena which represent the reality in its essence, the reality in sé (also known as transcendental reality). There is the impression that the "Kantian noumenon" is reflected in the pages of Mécanique Analytique. A mechanical world of ideal laws that imply the phenomenal and empirical world; a platonic world that interprets Nature, but so perfect that it is not able to be represented consistently and opportunely through illustrative figures. Citing Mathieu [8]: "If...we want to find the features of an objective reality, we must turn to a concept that is not based on experience; or, in Kantian language, which is a priori”. A significant example of such an a priori concept can be represented by the Principle of Virtual Work, which Lagrange considered an axiom. An analogous definition can be found, almost two centuries later, in Karl Popper's Critical Rationalism and conjectures [9].

The doctrine of this a priori concept is precisely what Kant referred to as "metaphysics". While the direct study of Nature is the duty of physics, metaphysics precedes it, knowing the rational structure of reality without the need to go back to experience. Kant used the term "rational" in the same way it appears in the expression "rational mechanics", intended as the science of motion which does not need to go back to experience. It can a priori construct the representation of motion, as it has at its disposal the primary forms of intuition: space and time.

More generally speaking, Kant suggested to Science the programme to explain mechanically and without finalities all the natural forms. It is interesting to observe how Kant refers to space by its traditional name "ether", considering it not as a physical matter but rather as an a priori principle [8]. 

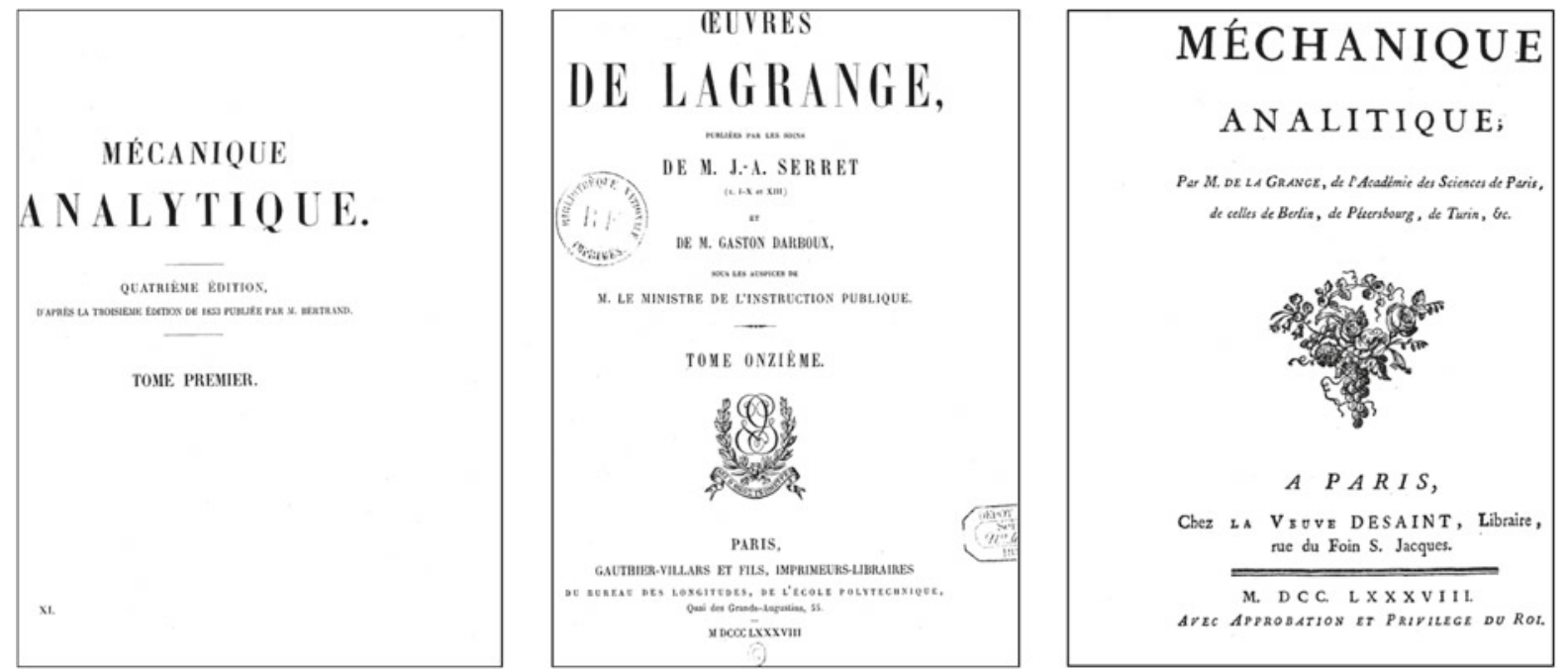

Fig. 1 Title page of the 1st edition of Mécanique Analytique, from the 11th volume of the work Oeuvres de Lagrange and the 4th edition of Mécanique Analytique

\subsection{The second edition of Mécanique Analytique}

In this section a comparison is proposed between the first edition [10] of Lagrange's Mécanique Analytique (1788) and the second edition of the treatise [11, 12], which was divided into two volumes, of which the first appeared in 1811, while the second was publishes after his death in 1815 . As the second edition is very rare, in the subsequent analysis reference will be made, among the different subsequent editions of Mécanique Analytique, to the fourth [13], contained in the XI Volume of the Oeuvres de Lagrange published in 1888 by M.J.-A Serret and M.G. Darboux. As indicated in the preface to the fourth edition, this work in fact represents, in all intents and purposes, a reprint of the second edition of Méchanique Analytique, with the addition, at the foot of the page, of the notes of the mathematician M.J. Bertrand. Both the first and the fourth editions can be consulted on the Web at the site of the French National Llbrary, "Gallica" (http:// gallica.bnf.fr).

The second edition of Mécanique Analytique (1811) [11, 12] presents significant integrations and enlargements compared to the first [10], which was published in 1788, as also remarked on by Lagrange himself in the preface to the work: "this is, from many points of view, a new work, on the same level, but more extensive. More space has been given to the development of principles, to the general formulae and to the applications, in which the solutions to the main problems that are part of the studies of Mechanics can be found". The principal differences that distinguish the second edition from the first can be discussed in detail by comparatively commenting on the indices of the two editions (see the title pages in Fig. 1).

\subsection{Statics}

The first part of the treatise, related to the problems of Statics, contains eight sections, all of which were expanded by Lagrange to various degrees. The first section, entitled "On different principles of Statics", contains a more complete analysis of the three principles of Statics, in other words, the Principle of Lever, the Principle of the Composition of Movements, and the Principle of Virtual Work, with new observations on the nature and on the connections that exist between them. In the second edition, under the title "General Statics formula for the equilibrium of any system of forces, in such a way to apply this formula", a more general "demonstration" of the Principle of Virtual Work is given for any number of forces in equilibrium [14]. Furthermore, the conditions that are necessary for a system of forces to be considered equivalent to each other are also given. The third section, entitled "General properties of a system of bodies, deduced from the previous formula", deals in a more intuitive way with the formulae 
of instantaneous rotation movement and of the composition of movements. Likewise, Lagrange deduced the vectorial theory of the composition of movements, proposing a new demonstration of the maximum and minimum that occur in equilibrium states. In the fourth section, titled "Simpler and more general ways of using the equilibrium formula proposed in the second section", Lagrange proposed more general and simpler formulae to resolve mechanical problems on the basis of the méthode des variations, which is today known under the name of Variational Calculus, thus defined by the Author: "for the little there is at the current of the principles of Differential Calculus, the method to determine the largest and smallest ordinates of the curves is known; but questions of maxima and minima of a higher type exist, which, although depending on the same method, are not so easy to resolve. They are the ones in which one deals to find the curves themselves, in which a certain integral expression gives either a maximum or a minimum with respect to all the other curves". The fifth ("Solutions of the different problems of Statics") and the sixth sections ("On the principles of Hydrostatics") of the second edition instead only show slight additions compared to the previous edition. In the seventh section ("On the equilibrium of incompressible fluids") Lagrange proposes yet again, but with renewed methodological rigour, the study of the interaction between a fluid mass and a rigid body, and the relative problem of their equilibrium. The eighth section ("On the equilibrium of compressible and elastic fluids") remains practically unchanged compared to what was written in the first edition.

\subsection{Dynamics}

The second part of the treatise, related to the problems of Dynamics, shows a greater number of additions than the first part. In the first section ("On the different principles of Dynamics"), a more complete historical review of the principles of Dynamics is given. In the second section ("General Dynamics formula for the movement of a system of bodies animated by any force"), Lagrange demonstrates under what conditions the general Dynamics formula is given and, as a consequence, that the equations resulting from the movement of a system of bodies are independent of the chosen reference system in space. In the third section ("General properties of movement deduced from the previous formula"), more details are provided on the properties of the movement of the centre of gravity and on the trajectories of a system of bodies. In this manner, the theory of the principal rotation axes is introduced and some theorems on the rotation of a rigid body or of a system of bodies, due to the action of an external impulse, are demonstrated. The fourth section ("Differential equations for the solution of all Dynamics problems") remains almost unchanged compared to the previous edition.

The fifth section ("General approximation methods of dynamics problems, on the basis of variations of the arbitrary constants") is instead completely new and it proposes a re-elaboration of the theory of variations of the arbitrary constants applied to mechanics which had been the subject of three articles that appeared between 1808 and 1811 in the dissertation presented at the Institut de France (Fig. 2). This contribution to analytical mechanics links up with the great research by Lagrange on Celestial Mechanics dating back to the period in Berlin, but also with his research related to the differential equation theory from the same period. On 22 August 1808 Lagrange presented his "Dissertation on the theory of variations of the elements of the planets" [15]. This dissertation was then followed by that "On the general theory of variations with arbitrary constants" [16], which was presented on 13 March 1809 at the Institut de France, in which the method is generalized to all mechanics problems. Finally, Lagrange presented an even more simplified and definitive version of the theory on 19 February 1810 , entitled "Second dissertation on the general theory of the variations of arbitrary constants in all mechanics problems" [17], which then became the basis of the second edition of Mécanique Analytique.

The sixth section ("On small oscillations of any system of bodies"), which corresponds to the fifth section of the first edition of Mécanique Analytique, is expanded with various examples and it concludes with the theory of vibrating chords, a subject which had already been studied by the Author in Mémoires de Turin.

\section{The influence of Lagrange's studies on modern mechanics}

The derivation of most of the fundamental laws that govern solid and fluid mechanics, through the 

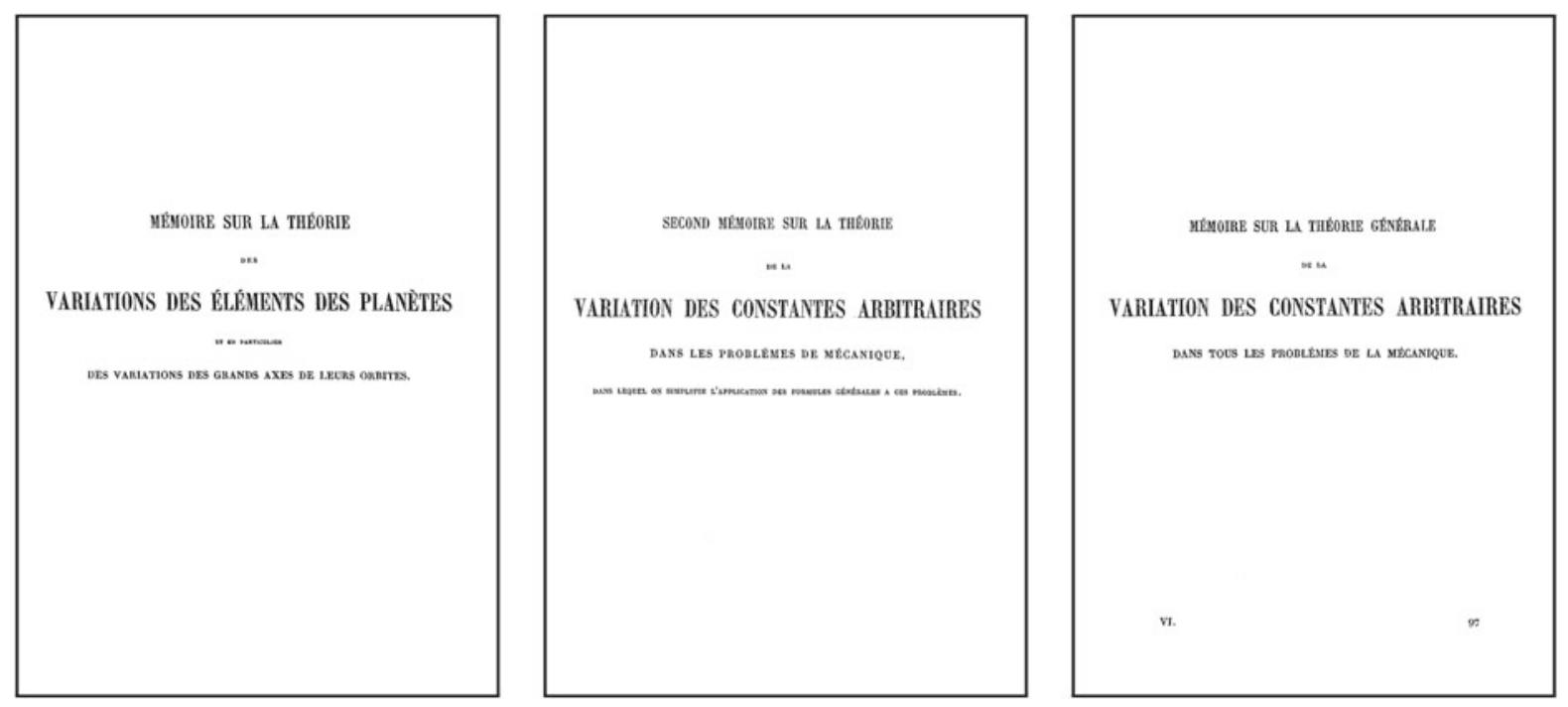

Fig. 2 Title page of the dissertation presented by Lagrange at the Institut de France, currently collected in the VI volume of the work Oeuvres de Lagrange

application of the Calculus of Variations to mechanics problems, are due to Lagrange. For many, starting from Mach ([18], p. 457), "analytical mechanics has reached the highest degree of perfection thanks to the work of Lagrange". Hankins ([19], p. 29) even wrote that Lagrange "brought rational mechanics to the maximum generality and abstraction that could be reached in the Enlightenment era". On the other hand, d'Alembert (1717-1783) had already proposed reestablishing the theory of mechanics in a new way from the Newtonian theory. However, only Lagrange was able to formulate a complete and precise theory, declaring it as an alternative to that of Newton ([11, 12], p. 159): "Mechanics became a new science in the hands of Newton... I have here offered you a new means to facilitate this research".

\subsection{The principle of virtual work}

In the new formulation of mechanics proposed by Lagrange, the quantity of primary importance is no longer the force, but the work done by forces for infinitesimal arbitrary movements. On the other hand, various scholars have discussed about whether Lagrange's formulation is or not equivalent to Newton's and whether it can accordingly be considered as a real innovation (see, for example, the review by Truesdell [6]). Lagrange stated that "the work will unify and present the various principles so far found under the same point of view [of the principle of virtual work]" ([11, 12], p. 2).

However, it is interesting to observe how Lagrange, though declaring that he based himself on the principle of virtual work (or, as it was called then, of the virtual velocities), which was generally considered "as a kind of axiom of mechanics", attempted just the same to deduce it from other more general principles $([11,12]$, p. 12). "[...] we shall expound this formula in all its interpretations; we shall try to present it in an even more general way than has been done up to now". Lagrange thus arrived at the formulation of the following expression $([11,12]$, p. 21$)$ : “the principle of virtual velocities can be considered as very general by expressing it in the following manner: if any system, composed of any number of points or bodies, each of which solicited by any force, is in equilibrium; and if this system is given any small movement, in virtue of which each point travels by an infinitely small displacement, which shall express its virtual velocity - then the sum of the forces, each one multiplied by the displacement travelled (in its direction) from its point of application, shall always be equal to zero; considering the displacements travelled in the same direction of the forces as positive and small; and the travelled displacements in opposite direction as negative" . 
As observed by Drago [20], this demonstration in fact did not succeed for Lagrange nor for the others who later undertook the same task. Jacobi (1743-1819) stated that this was "a proposition without demonstration", since "no demonstration is possible". Some 30 years after Lagrange's work appeared, Cossali (1745-1815), referring about the famous virtual work equation, exclaimed: "Oh awesome equation! Oh immense equation! Equation enriched with truth, full of light! I cannot express your vastness and, at the same time, your simplicity, but to give you an image (such that human intellect can be granted) of that infinite and so simple act, with which the Supreme Being contemplates all equilibria, and the movements in the Earth, in each of the innumerable Suns, in each of the planets acting as their corona, in the entire machine of the universe, in the infinite possible machines throughout the world [...]". More recently, Levi-Civita and Amaldi ([21], vol. 1, p. 708) considered it a principle and not a theorem: "from the physical point of view, the principle of virtual work is justified by showing that it takes place (that is, appears to comply with experience) in many particular cases which, by natural and almost necessary deduction, can be considered valid in general". In a similar way, Sommerfeld ([22], p. 51) considers it a premise that cannot be demonstrated: "we are very far from giving a general demonstration of this premise".

Recent developments on this theme have concerned the study of the characteristics of duality between static matrix operator, which relates the constraint reactions with the applied external loads, and kinematic matrix operator, that connects the movements of a generic point of a rigid body to those of a representative pole (or reduction centre) of the system [23]. This property, which is expressed by the fact that the static matrix is the transpose of the kinematic one, implies the principle of virtual work for rigid body systems, and viceversa. Moreover, the duality of static and kinematic operators arises as a direct consequence of the equations that describe the equilibrium and the kinematics of a rigid body. If we consider a plane rigid body subject to the action of $n$ generalized forces of components $H_{\mathrm{i}}, V_{\mathrm{i}}$ and $M_{\mathrm{i}}$ with respect to the Cartesian reference system defined by the versors, $\vec{i}, \vec{j}$, the resultant $\{R\}$ of this system of forces shall be given by:

$$
\begin{aligned}
\{R\} & =\left[\begin{array}{c}
F_{x} \\
F_{y} \\
M
\end{array}\right]=\sum_{i}\left[\begin{array}{ccc}
1 & 0 & 0 \\
0 & 1 & 0 \\
-\Delta y_{i} & \Delta x_{i} & 1
\end{array}\right]\left[\begin{array}{c}
H_{i} \\
V_{i} \\
M_{i}
\end{array}\right] \\
& =\sum_{i}\left[A_{i}\right]^{\mathrm{T}}\left\{F_{i}\right\}
\end{aligned}
$$

where $\left(P_{\mathrm{i}}-O\right)$ represents the position vector of the application point of the generic force $\left(H_{\mathrm{i}}, V_{\mathrm{i}}\right)^{\mathrm{T}}$ with respect to the pole $O$. In a similar way, the kinematic equations that connect the generalized movements of a generic point $P_{\mathrm{i}}$ of the rigid body with those of the pole $O$ give:

$$
\begin{aligned}
\left\{s_{i}\right\} & =\left[\begin{array}{c}
u_{i} \\
v_{i} \\
\varphi_{i}
\end{array}\right]=\left[\begin{array}{ccc}
1 & 0 & -\Delta y_{i} \\
0 & 1 & \Delta x_{i} \\
0 & 0 & 1
\end{array}\right]\left[\begin{array}{c}
u_{O} \\
v_{O} \\
\varphi_{O}
\end{array}\right] \\
& =\left[A_{i}\right]\left\{s_{O}\right\}, \forall i=1, \ldots, n .
\end{aligned}
$$

The work done by the resultant $\{R\}$ for the movement of pole $O$ can now be related to the total work done by the single applied forces:

$$
\begin{aligned}
\{R\}^{\mathrm{T}}\left\{s_{O}\right\} & =\sum_{i}\left(\left[A_{i}\right]^{\mathrm{T}}\left\{F_{i}\right\}\right)^{\mathrm{T}}\left(\left[A_{i}\right]^{-1}\left\{s_{i}\right\}\right) \\
& =\sum_{i}\left\{F_{i}\right\}^{\mathrm{T}}\left[A_{i}\right]\left[A_{i}\right]^{-1}\left\{s_{i}\right\} \\
& =\sum_{i}\left\{F_{i}\right\}^{\mathrm{T}}\left\{s_{i}\right\} .
\end{aligned}
$$

Should the resultant $\{\mathrm{R}\}$ vanish in order to guarantee equilibrium of the rigid body, the first member of Eq. (3) is annulled and the equation of the principle of virtual work is derived:

$\{R\}=\{0\} \Leftrightarrow \sum_{i}\left\{F_{i}\right\}^{\mathrm{T}}\left\{s_{i}\right\}=0$.

The property of duality of the static and kinematic matrices is also verified for a three-dimensional body, for which, in lieu of Eqs. (1) and (2), the following expressions are obtained:

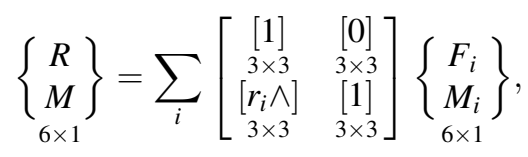

and

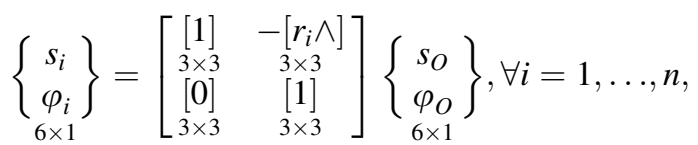


where the operator $\left[r_{i} \wedge\right]$ is an antisymmetric matrix derived directly from the definition of the operator of vectorial product:

$\left[r_{i} \wedge\right]=\left[\begin{array}{ccc}0 & -\Delta z_{i} & \Delta y_{i} \\ \Delta z_{i} & 0 & -\Delta x_{i} \\ -\Delta y_{i} & \Delta x_{i} & 0\end{array}\right]$.

Finally, it can be noted how the definition of vectorial product, which represents the essence of the previous demonstration, was introduced by Hamilton (1805-1865) only in 1843 [24, 25] and became widely used in engineering practice just in the second half of the twentieth century [26, 27]. Such a formulation can also be extended to rigid body systems connected to each other through internal constraints, as has been illustrated extensively in [23].

The property of duality has also been verified in the various types of deformable solids [23]. In this context, the principle of virtual work represents an essential instrument for the correct determination of the static matrix, which, in this case, connects the internal forces to the external ones, and the kinematic matrix, which relates the deformation characteristics to the generalized displacements of the system. In this way, it is possible to deduce the static and kinematic matrix operators for all structural elements, such as beams of straight or curvilinear axis, plates or shells, as well as for three-dimensional solids, with important implications concerning the Finite Element Method [23].

\subsection{The calculus of variations}

In Lagrange's time, the theory of the calculus of variations was inspired by the metaphysic principle of least action, which affirms that the history of motion chosen by a mechanical system is such as to minimise the integral $S$ of the Langrangian of the system, $L=T-V$, where $T$ represents the kinetic energy and $V$ the potential energy:

$S=\int_{0}^{t} L \mathrm{~d} t$.

Lagrange, in his treatise Mécanique Analytique, proposed describing the configuration of a generic mechanical system, defined by function $L$, through the use of generalized coordinates, among which, apart from the space coordinates $q_{i}$, time $t$ was included for the first time. Applying the calculus of variations to the functional $S$, Lagrange determined the conditions that are necessary and sufficient for the lagrangian to satisfy so that $S$ is an extremum. These conditions are today called Lagrange equations:

$\frac{d}{d t} \frac{\partial L}{\partial \dot{q}_{i}}-\frac{\partial L}{\partial q_{i}}=0$

The innovations brought about by this theory of mechanics, compared to that of Newton, have been highlighted by Lanczos [28] and they concern several aspects. First of all Lagrange's analytical mechanics proposed studying a system as a whole, rather than the single mass-points. It considers a scalar function, the Lagrangian $L$, which determines the entire dynamics of the problem, instead of a force acting on each moving particle. Such a formulation does not explicitly consider the constrain reactions and develops the whole system of equations of motion starting from a unitary principle, which minimises a certain quantity, i.e., "the action", which can be expressed in generalized coordinates. Maurice also observed that, "after having recognised, in his work on the motion of the moon [29], the dependence of the principle of least action on that of the virtual velocities, Lagrange, in Mécanique Analytique, fully demonstrated that the principle of least action is a consequence of that of the virtual velocities".

The calculus of variations introduced by Lagrange has inspired many important studies, not only pertaining to the mechanics of rigid bodies, but also to that of deformable bodies. In this wider field, the role of action $S$ for which the extremum is searched, is represented by the total potential energy of the elastic body, $W$, defined as the difference between the elastic deformation energy and the potential energy of the applied external forces. Again in this case, in close analogy with the study of rigid bodies, the variational formulation implies the operational formulation of the elastic problem, which is represented by Lamé's equation and by the equivalence conditions at the boundary, as the least action $S$ implies Lagrange's differential equations (9), and viceversa [23].

The main consequences of these implications regard the possibility of utilizing integral (or global) formulations as an alternative to differential (or pointwise) formulations, with a consequently minor request of regularity of the physical fields involved. Integral formulations in fact allow all the intrinsic relations of 
the dealt with problem to be synthesized in a single functional: field equations, boundary conditions, initial conditions, conditions dictated by the constraints and even conditions of discontinuity or non derivability of the involved physical fields. Finally, among the most peculiar current properties, integral formulations represent a very natural criterion to derive approximate methods. In the second half of the nineteenth century, the calculus of variations was applied by Kirchhoff (1824-1887) to the plate theory, by Green (1793-1841) and Kelvin (1824-1907) to the theory of elasticity, and, through the studies of Castigliano (1847-1884) and Menabrea (1809-1896), to structural mechanics. At the beginning of the twentieth century, the approximate solution methods by Rayleigh (1842-1919), Ritz (1878-1909) and Galerkin (1871-1945), from which the more recent finite element method is derived [30], were on one hand developed, while, on the other, greater theoretical foundation was given to variational methods with the contributions of Volterra (1860-1940), Fréchet (1878-1973), and Hilbert (1862-1943).

Again in the ambit of calculus of variations, another important contribution by Lagrange to Mechanics, which is still today a fruitful field of research, concerns the study of the extremum of a functional subject to constraint conditions. Both Euler (1707-1783) and Lagrange analysed this problem and arrived at the formulation of the multiplier concept. In mechanical jargon, the variations of the auxiliary conditions expressed by the constraints, each of which multiplied by a constant that has to be determined, which is known as the Lagrange multiplier, must be added to the infinitesimal virtual work.

In the Mécanique Analytique, Lagrange proposes an original physical interpretation of the multipliers: such constants can be considered as moments of force acting on the moving particle, in order to maintain the kinematic conditions expressed by the constraints satisfied. Lagrange analysed the problems characterised by constraints expressed in terms of equalities, and only in 1951 did Khun and Tucker [31] extend the multiplier method to constraints expressed in terms of inequalities. These developments, inspired by the work of Lagrange, are particularly relevant from an engineering point of view and concern many different aspects. For example, in the field of the plasticity theory, Lagrange's multiplier method can be used to impose the satisfaction of the inequality constraint due to the fact that the stress state in each point of a body should fall within the yield surface $[32,33]$. On the other hand, in contact mechanics, the condition of unilateral constraint on the border of the domain [34] is a typical example of constraint expressed in terms of inequality. Lagrange's multiplier method has also been used in optimisation problems subject to constraints; reference can be made, for example, to Sacchi Landriani [35] and to Cinquini and Rovati [36]. Finally, this method has recently been applied to impose boundary and interface conditions in the meshless type finite element formulations that are used in fracture mechanics [37].

\subsection{The method of variation of the arbitrary constants}

As far as the integrations to the second part of the Mécanique Analytique treatise are concerned, the theory of variations of the arbitrary constants surely represents one of the most important innovations, so much so that Lagrange can be considered the forerunner, ahead of his time by almost a century and a half, of that branch of differential geometry that goes under the name of Symplectic Geometry [38, 39].

In this theory, considered in the field of mechanics, the arbitrary constants are the constants that appear in the expression of the general solution of Lagrange's equations. In this context, Lagrange attempted to propose a simplified method to deal with the complex problem of the movement of the planets. It was in fact well known that, in order to characterise the motion of a body subject to the universal law of gravity, six integration constants are necessary, five of which are necessary to identify the conic that describes the trajectory of the celestial body in space, and one which is needed to define the position at a given instant on such an orbit. Kepler (1571-1630), neglecting the effect of the interaction of the planets, solved this problem and summarised it in fundamental laws.

In order to describe the motion of the celestial bodies in a more accurate manner, Lagrange thought of considering the influence of the set of planets on one of these planets as a perturbation. The orbit of the planet can be considered as momentarily influenced by the perturbation, but after the collision, which is comparable to the instantaneous impact of a small asteroid with the celestial body, it goes back to being a crossed conic that respects Keplero's laws. The effect 
of the permanent perturbations suffered by the celestial body, due to the interaction between the planets, can be considered as the result of a series of infinitesimal impulses received in a continuous way by the planet. The effect of the perturbing forces on the planet is therefore reduced to an infinitesimal and continuous variation of its orbit and the perturbed movement of the planet is thus described, in the space of the six integration constants, by a differential equation.

On the basis of mechanics laws, the variation of the coordinates that describe the position of the planet (or, in jargon, its elements) are generally proportional to the resultant of the perturbing forces and the coefficients of proportionality are in turn a priori of the time functions, of the position and of the velocity. Through the use of the theory of variation of the arbitrary constants, Lagrange demonstrated how this differential system can be transformed into another, apparently more complex system in which, however, the coefficients of the perturbing forces become independent of time, thus simplifying the problem considerably. Lagrange also underlined how this method can be applied to any mechanics problem, regardless of the number and type of parameters necessary to describe it.

The transformation proposed by Lagrange leads to the definition of the so-called "Lagrange parenthesis". In short, Lagrange defined the following differential operator, where $r_{i}$ and $v_{i}$ are, respectively, the components of the position vector and the velocity vector with respect to the Cartesian reference system:

$[a, b]=\sum_{i=1}^{3} \frac{\partial r_{i}}{\partial a} \frac{\partial v_{i}}{\partial b}-\frac{\partial v_{i}}{\partial a} \frac{\partial r_{i}}{\partial b}$.

The three remarkable properties this parenthesis benefits from were used as the basis of Symplectic Geometry, a name coined by the mathematician Hermann Weyl (1885-1955) in 1939 [40], on the basis of the Greek root $\sigma \nu \mu \pi \lambda \varepsilon \kappa \tau \imath \kappa о \zeta$, a translation of the Latin word complexus. This generalisation has become the foundation of an active field of mathematical topology which deals with the study of non degenerate differential manifolds of equal sizes. In this generalisation, the notion of distance is lost, while at the same time the notion of orientated area is conserved. Furthermore, as no simplex forms defined on the differential manifold of odd dimensions exist, and as the two-dimension is completely banal, it is possible to comprehend how this form of geometry, unlike that of Euclid, is not easy to represent.

Acknowledgments The present contribution is dedicated to the memory of the late Professor Dionigi Galletto, who encouraged and induced the first author to study the figure and the work of Lagrange.

\section{References}

1. Carpinteri A, Paggi M (2006) Sulla seconda edizione della Mécanique Analytique di Lagrange: lettura critica e prospettive attuali. In: Sfogliando la Méchanique Analitique, Giornata di Studio su Louis Lagrange, Istituto Lombardo, Incontri di Studio, vol 46, pp 109-130

2. Tricomi FG (1964) Sguardo generale all'opera di Luigi Lagrange. In: Truesdell C (ed) Atti del Convegno Lagrangiano, vol 98. Accademia delle Scienze, Torino, pp 8-19

3. Pepe L (1993) Lagrange e i suoi Biografi. In: Burzio F, Lagrange (eds) Prefazione all'Opera di Filippo Burzio. UTET, Torino, pp XI-XLIII

4. Mazzone S, Roero CS (2002) La tradizione leibniziana e i contributi di Euler e Lagrange. In: Mazzone S (ed) Storia della Scienza, vol 6 (L'Età dei Lumi). Istituto Enciclopedico Treccani, Roma, pp 388-414

5. Burzio F (1963) Lagrange. UTET, Torino

6. Truesdell C (1968) Essays in the history of mechanics. Springer, New York

7. Bell ET (1986) A lofty pyramid: Lagrange. Cap. 10 in men of mathematics: the lives and achievements of the great mathematicians from Zeno to Poincaré. Simon and Schuster, New York, pp 153-171

8. Mathieu V (1988) Kant. In: Severino E (ed) Filosofia: Storia del Pensiero Occidentale, vol 6. Curcio Editore, Roma, pp 1000-1043

9. Carpinteri A (1995) La tendenza nella fisica al superamento degli schemi precostituiti: Il caso dei sistemi complessi, Prolusione d'apertura del $98^{\circ}$ anno dell'Accademia di Santa Teodora, Caserta, pp 11-45

10. Galletto D (1991) Lagrange e la Mécanique Analytique, Memorie dell'Istituto Lombardo-Accademia di Scienze e Lettere, Classe di Scienze Matematiche e Naturali, vol XXIX, Memoria 3

11. Lagrange J-L (1788) Méchanique analitique, I edizione, Desaint, Paris

12. Lagrange J-L (1888) Mécanique Analytique. In: Joseph A (ed) Euvres de Lagrange, vol XI, IV edn. Gauthier-Villars, Paris

13. Lagrange J-L (1811) Méchanique analitique, II edn. Courcier, Paris

14. Capecchi D (2002) Storia del Principio dei Lavori Virtuali. Hevelius, Benevento

15. Lagrange J-L (1877) Sur la théorie des variations des éléments des planètes et en particulier des variations des grands axes de leurs orbites. In: Euvres de Lagrange, vol VI, Gauthier-Villars, Paris, pp 713-768. (read the 22 Aug 1808 at the Institut de France) 
16. Lagrange J-L (1877) Sur la théorie générale de la variation des constantes arbitraires dans tous les problèmes de la mécanique. In: Euvres de Lagrange, vol VI, Gauthier-Villars, Paris, pp 771-805. (read the 13 Marzo 1809 at the Institut de France)

17. Lagrange J-L (1877) Second mémoire sur la théorie générale de la variation des constantes arbitraires dans tous les problèmes de la mécanique. In: Euvres de Lagrange, vol VI, Gauthier-Villars, Paris, pp 809-816. (read the 19 Feb 1810 at the Institut de France)

18. Mach E (1883) Die Mechanik in ihrer Entwicklung historisch-kritisch dargestellt (La Meccanica nel suo Sviluppo Storico-Critico, Boringhieri, Torino, 1968)

19. Hankins TL (1970) Jean d'Alembert. Science and enlightenment. Clarendon Press, Oxford

20. Drago A (1993) The principle of virtual works as a source of two traditions in 18th century mechanics. In: Bevilacqua $\mathrm{F}$ (ed) History of physics in Europe in 19th and 20th centuries. SIF, Bologna, pp 69-80

21. Levi-Civita T, Amaldi U (1974) Lezioni di Meccanica Razionale, vol 1, 2nd edn. Zanichelli, Bologna

22. Sommerfeld A (1952) Mechanics. Academic Press, New York

23. Carpinteri A (1997) Structural mechanics: a unified approach. Taylor and Francis, London

24. Hamilton WR (1858) Letter from Sir W.R. Hamilton to Professor P.G. Tait, 15 Oct 1858

25. Hamilton WR (1865) Letter from Sir W.R. Hamilton to Rev. Archibald H. Hamilton, 5 Aug 1865

26. Giorgi G (1947) Metodi di calcolo vettoriale e spaziale. Notizie critiche e comparative, Cap XLII. In: Berzolari L (ed) Enciclopedia delle Matematiche Elementari e Complementi. Ulrico Hoepli, Milano

27. Crowe MJ (1985) A history of vector analysis: the evolution of the idea of a vectorial system. Dover, New York
28. Lanczos C (1968) The variational principles of mechanics. Dover, New York

29. Lagrange J-L (1764) Recherches sur la libration de la Lune, dans lesquelles on tache de résoudre la Question proposée par l'Académie Royale des Sciences pour le prix de l'année 1764. In: Euvres de Lagrange, vol VI, Gauthier-Villars, Paris, pp 5-66

30. Zienkiewicz OC (1971) The finite element method in engineering science. McGraw-Hill, London

31. Kuhn HW, Tucker AW (1951) Nonlinear programming. In: Proceedings of the 2nd Berkeley symposium. University of California Press, Berkeley, pp 481-492

32. Prager W (1942) Fundamental theorems of a new mathematical theory of plasticity. Duke Math J 9(1):228-233

33. Maier G (1972) Plasticity, Enciclopedia della Scienza e della Tecnica (EST). Mondadori, Milan, pp 769-784

34. Fichera G (1964) Problemi elastostatici con vincoli unilaterali, il problema di Signorini con ambigue condizioni al contorno. Memorie dell'Accademia Nazionale dei Lincei VIII(7):91-140

35. Sacchi Landriani G (1985) Lagrange multipliers methods for optimization with constraints. In: Prager W, Save M (eds) Structural optimization. Plenum Press, New York

36. Cinquini C, Rovati M (1995) Optimization methods in (structural) engineering. Eur J Mech A Solids 14:413-437

37. Carpinteri A, Ferro G, Ventura G (2001) An augmented Lagrangian element-free (ALEF) approach for crack discontinuities. Comput Methods Appl Mech Eng 191:941-957

38. Souriau J-M (1986) La structure symplectique de la mécanique décrite par Lagrange en 1811. Mathématique et Science humaines 94:45-54

39. Iglesias P (1995) Les origins du calcul symplectique chez Lagrange. Le journal de maths des élèves 1(3):153-161

40. Weyl H (1939) Classical groups: their invariants and representations. Princeton University Press, Princeton 